\title{
Proactiveness and Organizational Resilience of Food and Beverage Manufacturing Firms in South-South Nigeria
}

\author{
Samuel Arome Baba ${ }^{1 *}$ \\ Christine Adaobi Nwuche ${ }^{2}$ \\ Department of Management ${ }^{1,2}$ \\ University of Port Harcourt, Nigeria ${ }^{1,2}$
}

\begin{abstract}
The ever-changing business environment has made it imperative for business organizations to reach beyond risk management and move towards a more holistic view of business health and success. These business organizations must anticipate, prepare for, respond and adapt to incremental change and sudden disruptions in order to survive and prosper. This preparation is the main ingredient to the organization's resilience. This study is an empirical work on the relationship between proactiveness and resilience of food and beverage manufacturing firms in south-south Nigeria. A cross-sectional survey design was adopted, while primary data was collected via the administration of a structured questionnaire. 321 copies of the questionnaire were distributed to the respondents and 297 copies were retrieved showing 93\% retrieval rate. Data analysis was carried out with the aid of Statistical Package for Social Sciences (SPSS). The result of the analysis affirmed the alternate hypotheses which stated that proactiveness positively correlates with the measures of organizational resilience. Thus, concluded that proactiveness promotes resilience of the food and beverage manufacturing firms in south-south Nigeria. The study also recommended that organizational work arrangements can be structured to allow for less stringency in supervision so that workers can express themselves in proactive ways; management should be more attuned towards the potentials and creative capabilities of the subordinates and organizational systems can be patterned to link actions with implications for workers in such a manner that workers are motivated to be cautious but yet willing and open to risk taking such that could benefit and advance their position within the organization and also contribute to an overall advantage for the organization.
\end{abstract}

Keywords: Adaptability, Management of Vulnerabilities, Pro-activeness, Organization, Nigeria

*Corresponding author: Samuel Arome Baba; Email: barnabasy2k@yahoo.com DOI: https://doi.org/10.37227/JIBM-2021-04-781

\section{Introduction}

The dynamism in the business environment has forced businesses to find better ways of achieving their set goals and objectives, especially in Nigeria where we are constantly faced with the peculiarities of our own myriads of challenges. Hence, the need for organizations to be more proactive in ways that advance their resilience and continuity in business. James (2003) explains that a resilient organization is one that does not merely survive over a long 
time but also flourishes, passing the test of time. To expatiate this point Robert (2010) corroborates that organizational resilience entails a firm's capacity to maintain or restore an acceptable level of functioning despite perturbations or failures.

Several researches have been carried out over the decade as it relates to organizational resilience. For example, Umoh and Amah (2013) examined the relationship between knowledge management and organizational resilience in the manufacturing sector of Nigeria and found a positive and significant relationship the two constructs. Suggesting the knowledge management offers a substantial positioning of organizations that enhances their learning and ability to adapt. In the same vein, Ikiriko, Jaja and Eketu (2017) studied the relationship between performance management and organizational resilience. Their study shows that there is a positive association between the dimensions of performance management and the measures of organizational resilience.

Jaja and Amah (2014) in their own study also looked at the effect of mentoring on organizational resilience in the Nigerian manufacturing industry in Port Harcourt and found a positive association. Their study highlighted on the usefulness of supervisor-subordinate relationships in addressing skill gaps required for innovativeness and as such contributing towards organizational resilience. Agadah, Nwuche and Anyanwu (2016) investigated the effect of talent management on organizational resilience in Port Harcourt, Nigeria. Eketu and Ifionu (2015) studied the impact of firms' collaborative behavior on enterprise resilience of banks in Nigeria. Stressing that such collaborations are hinged on partnerships designed to not only generate social capital but to also cushion against possible adverse effects based on high-risk projects or endeavours. Nnamdi (2017) investigated the relationship between innovation and resilience of small-medium entrepreneurs in Port Harcourt, Rivers State.

This is as Sugarman (2001) points out that the capacities for proactiveness is often linked to start-up businesses and SMEs is primarily due to their size and capacity for flexibility and service fluidity. While the business environment maybe beyond the control of the organization, the actions and behaviour of the organization are considered its own responsibility. Hence, expectations are placed on food and beverage manufacturing firms to be more creative and pro-active in their activities, services and engagement of their market. James (2003) argued that proactiveness affords employees a platform where they can contribute meaningfully towards the development and design of services that are detailed according to their own experiences with customers of the organization (Naseer, Khawaja, Qazi, Syed, \& Shamim, 2021). This suggests first-hand learning about the satisfaction gaps as expressed by the customers of the organization. This in turn also helps in the identification of the areas of requiring attention such as the required service designs, expectations of relationship feature and possible organizational inclinations that are more advantageous or competitive.

Hence, proactiveness affords organizations a more substantial and competitive positioning within their environment and markets as it not only builds on feedback from the environment, it tends to also allow for the adoption of measures best suited in ensuring the organization remains abreast and aware of its environment, drives its capacity for change responsiveness and adaptability and also ensures organizations effectively address their vulnerabilities in a manner that assures them of operational continuity (Al-Omoush, SimónMoya, \& Sendra-García, 2020).

Considering the numerous previous research attempts on organizational resilience, there seems to be a dearth of knowledge on how proactiveness relates to organizational resilience. Thus, this study intends to fill this gap by examining the relationship between 
proactiveness and organizational resilience of food and beverage manufacturing firms in the South-south of Nigeria.

As a result of the se identified challenges-the Nigerian manufacturing sector is noted as being plagued with failures, high rate of closure, poor services and a low level of competitiveness given the growing level of localization from foreign organizations within the local markets. Such problems have also impacted negatively on the economy given its observed level of dependence and reliance on the export of goods and services which ought to be produced within the local manufacturing industry. This is as Jaja and Amah (2014) observed that the well-being and performance of the manufacturing industry invariably is a flection of the well-being and growth of the country or nation itself.

Based on the foregoing and the observed imperatives of proactiveness in the functionality of organizations, this study therefore investigates the relationship between proactiveness and organizational resilience of food and beverage manufacturing firms in the South-South of Nigeria.

\section{Research Questions/Hypotheses}

The following research questions address the features of the relationship between proactiveness and organizational resilience:

i. Is there a significant relationship between proactiveness and adaptability of food and beverage manufacturing companies in South-south Nigeria?

ii. Is there a significant relationship between proactiveness and situation awareness of food and beverage manufacturing companies in South-south Nigeria?

iii. Is there a significant relationship between proactiveness and management of vulnerabilities of food and beverage manufacturing companies in South-south Nigeria?

The study was guided by the following null hypotheses:

$\mathrm{HO}_{1}$ : There is no significant relationship between proactiveness and adaptability of food and beverage manufacturing companies in South-south Nigeria.

$\mathrm{HO}_{2}$ : There is no significant relationship between proactiveness and situation awareness of food and beverage manufacturing companies in South-south Nigeria.

$\mathrm{HO}_{3}$ : There is no significant relationship between proactiveness and management of vulnerabilities of food and beverage manufacturing companies in South-south Nigeria.

\section{Proactiveness}

\section{Literature Review}

Proactive people are individuals who always take the initiative of controlling their environment rather than reacting to events after they occur (Bateman \& Crant, 1993). Crant (2001) asserts that proactive people are more likely to succeed in their careers because they take the initiative to learn and develop their skills voluntarily while performing their jobs. Proactive people are therefore competent to work in a dynamic business environment because they strive to get the best out of their jobs. Generally, both production and service industries involve activities that require some degree of Proactiveness; like determination of the most appropriate products or services, active follow up on prospective customers and identification of unmet client needs. An employee that proactively engages in seeking new opportunities becomes knowledgeable of the potential markets and is able to make informed decisions. Previous studies have not clearly shown the link between proactive behaviour and intrapreneurship. In addition, the studies have not concluded how proactiveness correlates 
to other organizational factors. The study will therefore add empirical evidence on the relationship between these variables.

The level of entrepreneurial proactiveness in a firm often decides the extent to which it will survive in a changing market, especially for SMEs which have limited resources and R\&D capability to sustainably compete with large companies (Naseer et al., 2021). Proactiveness is often defined as opportunity seeking and exploitation of resources that can be a source of innovation, competitive advantage and first-mover benefits in the marketplace (Eggers et al., 2013; Ireland et al, 2006). A forward-looking approach and a positive mindset can help the firm use existing techniques or adopt advanced knowledge to overcome impending change in the market place. However, a firm has maximum chances of enjoying first mover benefits.

However, for a firm to maximize its chance of enjoying first mover benefit, it needs to combine proactiveness with innovativeness and come up with a novel solution that is brand new to the market place and therefore, accepted as a breakthrough. Entrepreneurial orientation rests on the capability of a firm to use its existing resources to introduce new products or services in the marketplace or redefine its investments and develop processes and products that are completely new to the marketplace. Proactiveness has the capacity to not just project the firm into the future market but also shape the environment in the market and give new edge to existing competitive capabilities. Capitalizing in emerging markets is the main requisite of the spirit of proactiveness (Tang \& Hull, 2012).

Proactiveness is expected to be significant in securing superior firm performance (Baker \& Sinkula, 2009). It is easier for them to target premium markets and extract first entrant advantages like skimming the market much ahead of their competitors (Tang \& Hull, 2012; Lumpkin \& Dess, 2001). Needless to say, that in order to fulfil this requisite, a firm must be able to balance internal dilemmas between innovation pathways against challenges related to demands of contradictory nature on the firm by the external market environment that creates external pressure on the firm (Jansen et al., 2006). A firm therefore is able to learn the art of striking the balance between radical and incremental innovative actions to accomplish superior sustainable performances. A firm that is unable to strike this balance will end up becoming mediocre and uncompetitive in the market (Chang et al., 2011).

Proactiveness can be a drive for innovativeness since organizations with this orientation tend to start innovation protocols to meet the emerging customers or market needs (Nieto et al., 2013). The approach utilizes original designs, new markets creation, and new channels of distribution which are developed through due diligence and proactiveness (Al-Omoush et al., 2020). Alternatively, incremental innovations can be derived by exploiting current capabilities alongside seeking continuous upgradations as a result of incremental innovation that generate consistent and positive returns (Nieto et al., 2013). The firms expand on skills and the knowledge which exists currently. They also enhance the recognised designs and expand on the existing products and associated services, which increase the efficiency of existing distribution channels (Chang \& Hughes, 2012). Hence, it is only natural that incremental innovations build on existing knowledge and organization learning frameworks and bring into focus existing skills, structures and processes (Jansen et al., 2006).

\section{Organizational Resilience}

Organizational resilience can be active or passive (Kim, 2021). Passive resilience is demonstrated after the occurrence of an incident. It reflects how quickly an organization returns to normal without incurring major loss, damage or discontinuity. Passive resilience 
represents the ability to "bounce back" following a crisis or unexpected change. Active resilience is more than the ability to bounce back; it is a deliberated effort to develop the ability deal with future challenges. It involves identifying potential risks, developing early warning systems and taking proactive measures (Kim, 2020). Valastro (2011) identified four main objectives of organizational resilience and described them as resilience maturity levels. These are: decline, survive, bounce back and bounce forward. The higher the maturity level, the more resilient the organization becomes. In addition to these four levels. One additional level (Level 5) was added to Valastro's model, that is, "established culture of resilience" to represent the highest level of resilience (Ihab \& Salman, 2014).

Organization resilience may be mixed with other quite similar attributes such as flexibility, agility, and adaptability. Lengnick-Hall et al. (2011) distinguish these attributes from resilience. They see that flexibility, agility and adaptability reflect different origins and outcomes. Resilience is required often in an unexpected situation. Flexibility and adaptability can be seen as strategic capabilities which company need to have on an on-going basis (Kim, 2020). Resilience is organizations internal process to enhance competitiveness whereas in contrast adaptability is a need to try to fit to the challenges triggered by external requirements (Sachenko, 2020). Adaptability from that perspective aims to a new desired state in a new, externally determined equilibrium. Even though flexibility, adaptability and agility together may impact organization's resilience capability, none of these alone is sufficient to achieve it. (Lengnick-Hall et al. 2011).

There is not one agreed list of the characteristics of a resilient organization, though it is agreed that resilient organizations have certain common features. According to Mallack (1998), common to resilient organization is that they are able to sustain competitive advantage by effective actions to advance themselves. Organization shares decision-making power, which supports effective responses. When the organization is empowered to decision making, decisions don't require immediate approval and can be done under time pressure. This has positive impact to productivity and quality. (Mallack, 1998).

According to Coutu (2002), resilient organizations regularly ask if it truly understands and accepts the reality of its situation. Organizations are almost pessimistic when looking at the reality, which enables them to train to survive before the actual materialization of a change or crisis. Resilient organizations are able to see the connection between current difficulties and better future (Kim, 2020). Finding the meaning of hard times makes even difficult times bearable. Shared values are fundamental for resilient organizations. It is indeed the sharing, which makes it important. Even if the organization would be full of resilient individuals, it would not matter if all of them had their own vision of reality and future. In worst case, this could threaten the organization's future as decisions and actions would conflict. Resilient organization typically improvises solutions without obvious tools and are able to see opportunities where no one else. Improvising does not mean there are no rules or regulations - discipline actually increases resilience. (Coutu, 2002).

\section{Adaptability}

Adaptability has been empirically linked with firm performance (Marcoulides \& Heck, 1993). Some specialists demonstrated the existence of an important relationship between firm performance and adaptability, viewed as a set of cultural values. (Kotter \& Heskett, 1992; Gordon \& DiTomaso, 1992). These researchers state that organizations capable of better internalizing values leading to a superior ability that allows them to recognize and adapt to changing conditions are more likely to reap superior rewards. According to them, adaptability is a combination of two or more cultural values, including innovation and action 
orientation, that allow a firm to adjust to environmental conditions better than others, thereby, leading to superior performance. Adaptability is also linked to the concept of strategy and appears to be more complex than a simple set of cultural values (Chen, Xu, $\mathrm{Zhao}, \mathrm{Xu}, \& \mathrm{Lei}, 2020)$. The ability to adapt to changing conditions is an underlying premise of the strategic choice perspective (Child, 1972).

In literature, but also in practice, strategy and adaptability are closely related concepts. For instance, strategy is intended to help an organization to achieve success within its environment. In addition, strategy sets the organizational direction which will result in a superior competitive position within that environment. It is necessarily to state that there is an interrelationship between strategy and the changing organizational environment. In other words, a strategy is designed to help an organization adapt to a changing world. In a strategic sense, adaptability is the ability of a firm to form and execute an effective strategy. The ability to adapt, however, seems to include much more than just the ability to do strategy.

For organizations that operate in strongly competitive markets, strategists have to allow for future uncertainty and find ways of dealing with it. They have to be able to sense change very quickly and respond to it. They have to be more adaptive and find evolutional routes for the company's survival. Organizations that have taken adaptive routes have realized that to be adaptive, they need to spread accountability and responsibility more widely across the organization and have built cultures that are tolerant of change and risk. The rate of change for the companies' environment is significant, although in some areas, the extent of the change is hidden. For example, in the textile sector, if a company decides to add some changes to a model already in the production line, in order to make it more appealing to other categories of customers than those, to whom it was originally created for, that single change may be monumental, in approach, execution and consequences.

\section{Situation Awareness}

To ensure effective situation awareness, organizational members must share their knowledge relative to organization task and goals (vision and mission); their individual tasks; and organizational members' roles and responsibilities. To provide a solid base for building team situation awareness, organizational members need to have information that will help them develop relevant expectations about the entire organizational task (Kästle, Anvari, Krol, \& Wurdemann, 2021). When organizations lose focus, it puts them in a grey area where no one may be able to predict outcomes with any certainty thereby making process, product and administrative capability most difficult. During organization evolution, they set certain goals or targets to meet, such as speed of advance, waypoints, and soundings. When they are not met, organizations must question why and systematically begin to evaluate its present situation to determine what went wrong (Smit \& Wandel, 2006).

For organizations to maintain situation awareness for effective process, product and administrative actions, it must occur through effective communications and a combination of the following actions, vis-à-vis, recognize and make others aware when the organization deviates from standard procedures; monitor the performance of organizational members; provide information in advance; identify potential or existing problems; demonstrate awareness of task performance; communicate a course of action to follow as needed; demonstrate ongoing awareness of mission status; continually assess and reassess the situation in relation to the mission goal(s); and clarifying expectations of all organizational features (Baader, Borgwardt, Koopmann, Thost, \& Turhan, 2020). 


\section{Management of Vulnerabilities}

Often, vulnerability is defined by one of its causal properties, for example poverty. When analysing vulnerability however, one must be aware that not everyone suffers the same way in response to the same event (Delor and Hubert, 2000). Some researchers contend vulnerability cannot, and perhaps should not, be reduced into simplistic term (Watts and Bolhe, 1993). One of the most pressing challenges in modern vulnerability and disaster research may be to find ways of assessing the inherent vulnerability that exists in the daily life of the general population (Wisner \& Luce, 1993; Delor \& Hubert, 2000).

\section{Proactiveness and Resilience}

According to Lumpkin and Dess (1996), proactive activity refers to the firms' timely response to market needs or demands, as well as generating market opportunities. A formidable proactive strategic posture provides enterprises with capability to anticipate changes that may occur in the business environment or even exert influence on the business environment to their advantage (Lumpkin \& Dess, 2001). Similarly, Blesa and Ripolles (2003) opined that strong proactive thinking is most likely to provide business enterprises with diverse capabilities to predict the needs of customers as well as reactions of competitors in the marketplace. On the other hand, organizational capability entails the capacity of business establishments to scout, combine, and execute different set of resources with the main aim of delivering sound performance to the marketplace (Ho et al., 2016).

Also, Uddin et al. (2014) revealed that outstanding business performance in the marketplace to a large extent is dependent on the firms' capabilities to address the issues of uncertainties linked with fluctuations in customers' taste. Thus, this signifies that capabilities are a major source of distinction among firms in terms of high or low performance, superior or inferior performance, excellent or poor performance. Even though there is dearth of empirical evidence on the relationship between proactiveness and organizational capability, Rua et al. (2018) posit that firms with high responsive ability consider proactiveness to be a core input. Such firms remain committed to take first mover advantage by engaging in forward-looking as well as opportunity-seeking activities (Anderson et al., 2015; Tang et al., 2014). Thus, they are likely to generate robust knowledge about market trends and predict market preferences (Hao \& Song, 2016). By so doing, it improves firms' capabilities to align or integrate the right kind of resources to deliver value that best suit such market preferences.

Proactive firms also focus on developing capabilities that influence policy makers and shape the market to their own advantage in terms of market share or market position (Tang et al., 2014). Further, proactive activities enable firms to keep abreast with changes in technology and regularly strive to create and integrate resources to match technology advancement (Hao \& song, 2016). This further confirms the views of Lumpkin and Dess (1996) that if an enterprise maintains high proactive thoughts, such enterprise can predict the desires of emerging markets and pull resources together to satisfy the markets better than its competitors. From the foregoing, it can be argued that proactiveness plays a pivot role in capability building as it involves the display of opportunities seeking behaviour not only to satisfy immediate market wants but also the inculcation of forward-looking thoughts which can forecast future market needs accurately.

For instance, in typical settings like Nigeria, the demand for cool drinks is mostly high between the months of February and June (hot season weather). Given the trend of previous demand as well as the prevailing market situation as the season approaches, a proactive manufacturing food and beverage firm may be able to predict with some level of 
accuracy, the demand for drinks, and then make efforts to integrate and reconfigure resources to flood the market not just with drinks but chilled drinks better than its competitors. In doing so, this may be aligned to the guiding principles of dynamic capability theory of the firm which postulates that firm's superior performance and capacity for resilience in dynamic business environment is the outcome of integrating, reconfiguring, and building of resources, strategies, and capabilities (Teece 2007; Teece et al., 1997).

\section{Methodology}

The study adopted a cross-sectional survey design (Creswell, 2009, p. 3; FrankfortNachmias \& Nachmias, 2008, p. 88; Kothari \& Garg, 2014, p. 34). The target population for this study was all food and beverage manufacturing firms in Nigeria; however, given the highly uncertain and poor regulation of existing manufacturing setups and units that pervade the food and beverage sector of the manufacturing industry, an accessible population of 1614 managers and supervisors from the 6 registered food and beverage companies in the SouthSouth States of Nigeria (Akwa Ibom, Rivers, Cross Rivers, Bayelsa, Delta and Edo State) listed on the Manufacturers Association of Nigeria (MAN) 2018 directory was used for this study. A random simple sampling was applied to include sample size of 321 that was used for this study (Aldaihani \& Ali, 2019). In measuring the predictor variable (risk-taking), 4 items were used and they were modified to reflect the attributes and practices within food and beverage manufacturing firms in South-South, Nigeria. Each item was scaled on a 5point Likert ranging from $1-5(1=$ strongly disagree, $2=$ disagree, $3=$ undecided, $4=$ agree, and $5=$ strongly agree). The criterion variable (organizational resilience) was measured using three facets adapted from the study of Hamel (2008) - (a) adaptability (b) situation awareness, and (c) management of vulnerabilities. with each further assessed using 4 item instruments, adapted in line with the characteristics and attributes of the food and beverage manufacturing firms in the South-south of Nigeria. Each item was scaled on a 5-point Likert ranging from $1-5(1=$ strongly disagree, $2=$ disagree, $3=$ undecided, $4=$ agree, and $5=$ strongly agree). Descriptive statistics was measured using mean and standard deviation. Spearman's rank order correlation coefficient was used for inferential statistics with the aid of Statistical Package for Social Sciences (SPSS).

\section{Discussion of Findings}

The relationship between proactiveness and the measures of organizational resilience as shown in the table below revealed a significant relationship at a 0.05 level of significance. The relationship between the variables shows that at a rho $=0.425$ and $\mathrm{P}=0.000$; proactiveness significantly enhances and drives adaptability, at a rho $=0.506$ and $\mathrm{P}=0.000$; proactiveness, significantly enhances and contributes towards situation awareness, and at a rho $=0.361$ and $\mathrm{P}=0.000$; proactiveness significantly impacts on the organizations ability to manage and control for the effect of events or the environment on its weak and vulnerable areas. 
Table 1: Relationship Between Proactiveness and Organizational Resilience Dimensions

\begin{tabular}{|c|c|c|c|c|c|c|}
\hline & & & Proactive & Adapt & Aware & Vulnerable \\
\hline \multirow{12}{*}{$\begin{array}{l}\text { Spearman's } \\
\text { rho }\end{array}$} & \multirow{3}{*}{ Proactive } & $\begin{array}{l}\text { Correlation } \\
\text { Coefficient }\end{array}$ & 1.000 & $.425^{* *}$ & $.506^{* *}$ & $.361^{* *}$ \\
\hline & & Sig. (2-tailed) & & .000 & .000 & .000 \\
\hline & & $\mathrm{N}$ & 297 & 297 & 297 & 297 \\
\hline & \multirow{3}{*}{ Adapt } & $\begin{array}{l}\text { Correlation } \\
\text { Coefficient }\end{array}$ & $.425^{* *}$ & 1.000 & $.636^{* *}$ & $.650^{* *}$ \\
\hline & & Sig. (2-tailed) & .000 & & .000 & .000 \\
\hline & & $\mathrm{N}$ & 297 & 297 & 297 & 297 \\
\hline & \multirow{3}{*}{ Aware } & $\begin{array}{l}\text { Correlation } \\
\text { Coefficient }\end{array}$ & $.506^{* *}$ & $.636^{* *}$ & 1.000 & $.629^{* *}$ \\
\hline & & Sig. (2-tailed) & .000 & .000 & & .000 \\
\hline & & $\mathrm{N}$ & 297 & 297 & 297 & 297 \\
\hline & \multirow{3}{*}{ Vulnerable } & $\begin{array}{l}\text { Correlation } \\
\text { Coefficient }\end{array}$ & $.361^{* *}$ & $.650^{* *}$ & $.629^{* *}$ & 1.000 \\
\hline & & Sig. (2-tailed) & .000 & .000 & .000 & \\
\hline & & $\mathrm{N}$ & 297 & 297 & 297 & 297 \\
\hline
\end{tabular}

Source: Data output, 2020

The result on the relationship between pro-activeness and organizational resilience advance a position which highlights on the positive role of pro-activeness in driving outcomes of organizational resilience. Proactiveness is critical strategic postures for firms to thrive in fast changing and competitive market environments (Covin \& Miller, 2014; Covin \& Wales, 2012). No wonder these strategic postures have attracted some scholarly interests and often recognized amongst the good predictors of high levels of firm performance. For instance, (Adams et al., 2017; Ambad \& Wahab, 2013; Amin, 2015; Lomberg et al., 2017; Tang et al., 2014; Uddin et al., 2014) studied the relationship between proactiveness and firm performance (Kam-Sing, 2014; Mamun et al., 2017). Extant literature reveals that majority of prior studies have established existence of positive and significant relationship between proactiveness and positive firm outcomes.

The thrust of the present finding adds to the stock of existing knowledge by providing possible answer to the questions of how and why proactiveness significantly impacts and contributes towards organizational resilience. Wiklund and Shepherd (2005) argued that an in-depth understanding of the tie between any strategic postures and firm behaviour may be explained by factors that are internal to the organization. In the same vein, Blesa and Ripollés (2003) and Uchegbulam et al. (2015) posit that relationships between proactiveness outcomes largely depend on the firm's capability to quickly respond to dynamics of market needs. Hence, this suggests that for better explanation of how and why proactiveness impacts and leads to positive firm behavioursuch as organizational capability, resilience and change readiness; it is important to identify its strategic perspective and posture.

A formidable proactive strategic posture provides enterprises with capability to anticipate changes that may occur in the business environment or even exert influence on the business environment to their advantage (Lumpkin \& Dess, 2001). Similarly, Blesa and Ripollés (2003) opined that strong proactive thinking is most likely to provide business enterprises with diverse capabilities to predict the needs of customers as well as reactions of competitors in the marketplace. On the other hand, organizational capability entails the capacity of business establishments to scout, combine, and execute different set of resources 
with the main aim of delivering sound performance to the marketplace (Ho et al., 2016). Also, Uddin et al. (2014) revealed that outstanding levels of organizational resilience to a large extent is dependent on the firms' capabilities to address the issues of uncertainties linked with fluctuations in customers' taste. Thus, this signifies that capabilities are a major source of distinction among firms in terms of high or low resilience, superior or inferior resilience, excellent or poor resilience.

\section{Conclusion and Recommendations}

Proactiveness as an attribute of individuals within the organization facilitates active thinking and planning which reflect change positioning and responsiveness and as such contributes toward improved outcomes of organizational resilience such as adaptability, situation awareness and the management of vulnerabilities

The relationship between proactiveness and organizational resilience is revealed to be positive and significant. The findings of this study demonstrate the role of proactiveness as been critical for organizations' level of adaptability, situation awareness and the management of vulnerabilities. Thus, in line with the findings of this study, the following recommendations are put forward:

i. Organizational work arrangements can be structured to allow for less stringency in supervision so that workers are able to express themselves in proactive ways and also be accountable for their actions and behaviour, such that their confidence and trust in their proactiveness is directly linked to their success and their contributions to the organization.

ii. Management should be more attuned towards the potentials and proactive capabilities of their subordinates and should be more flexible with regards to shared responsibilities and roles such that workers are offered the required opportunities and platforms to be pro-active in their roles and responsibilities.

iii. Organizations through their culture should allow for employees showcase their proactive skills. Management also needs to be proactive in reacting to environmental changes.

\section{Research Limitations and Future Directions}

This study built on the noted gaps of previous studies. It advanced a position on the relationship between proactiveness and organizational resilience anchored within the context of food and beverage manufacturing firms in Nigeria and by that offers a unique but well aligned perspective to the relationship between the variables. Nonetheless, it is delimited on the basis of its own context and focus, especially with regards to industry. On this basis the following suggestions are put forward:

i. Further studies could shift focus from the manufacturing industry to other industries such as those of banking, construction or telecommunication, but still within the context of Nigeria as a way of advancing knowledge on the possible changes or differences in outcome on the relationship between the variables (proactiveness and organizational resilience) that could be explained by the nature or context of these other industries.

ii. Further studies could also be extended to include a moderating variable such as organizational structure, organizational culture, and/or organizational politics.

iii. Finally, further studies could also adopt other theoretical frameworks and foundations in the interpretation, explanation and description of the relationship between the variables - proactiveness and organizational resilience. These could 
include the resource-based view theory, the transformational leadership theory and even the institutionalization theory; all of which address key support mechanisms and operational frameworks that facilitate proactiveness in the pursuit or achievement of organizational resilience.

\section{References}

Al-Omoush, K. S., Simón-Moya, V., \& Sendra-García, J. (2020). The impact of social capital and collaborative knowledge creation on e-business proactiveness and organizational agility in responding to the COVID-19 crisis. Journal of Innovation \& Knowledge, 5(4), 279-288.

Aldaihani, F. M. F., \& Ali, N. A. B. (2019). Impact of relationship marketing on customers loyalty of Islamic banks in the State of Kuwait. International Journal of Scientific \& Technology Research, 8(11), 788-802.

Baader, F., Borgwardt, S., Koopmann, P., Thost, V., \& Turhan, A.-Y. (2020). Semantic technologies for situation awareness. KI-Künstliche Intelligenz, 34(4), 543-550.

Baldwin, J. R. \& Johnson, J. (1996). Business Strategies in more and less innovative firms in Canada, Research Policy, 25, 785-804.

Blesa, A., \& Ripollés, M. (2003). The role of market orientation in the relationship between entrepreneurial proactiveness and performance. The Journal of Entrepreneurship, 12(1), 1-19.

Cainelli, G., Evangelista, R. \& Savona, M. (2004). The impact of innovation on economic performance in services, Service Industrial Journal, 24, 116-130.

Cainelli, G., Evangelista, R. \& Savona, M. (2006). Innovation and economic performance in services: a firm level analysis, Cambridge Journal of Economics, 30, 435-458.

Cornelia, W. (2004). The Politics of Trade Preferences: Business Lobbying on Service Trade in the United States and the European Union ( $\mathrm{PhD}$ Thesis). Institute d'Etudes Politiques de Paris.

Chen, C., Xu, L., Zhao, D., Xu, T., \& Lei, P. (2020). A new model for describing the urban resilience considering adaptability, resistance and recovery. Safety science, 128, 104756.

Creswell, J. W. (2009). Research design: Qualitative, quantitative, and mixed methods approaches. Los angeles: University of Nebraska-Lincoln.

Drucker, P. F., (1978). The Age of Discontinuity: Guidelines to our changing society. Harper Colophon Books: New York.

Drucker, P. F., (1985). Innovations-Management für Wirtschaft und Politik. 2. Auflage. Econ Verlag: Düsseldorf.

Frankfort-Nachmias, C., \& Nachmias, D. (2008). Research methods in the social sciences (seventh ed.). New York: Worth

Ho, T. C., Ahmad, N. H., \& Ramayah, T. (2016). Competitive capabilities and business performance among manufacturing SMEs: Evidence from an emerging economy, Malaysia. Journal of Asia-Pacific Business, 17(1), 37-58

Hult GTM, Hurley RF, Knight GA (2004). Innovativeness: Its antecedents and impact on business performance. Ind. Mark. Manage., 33: 429-438.

Jaja, S. A., \& Amah, E. (2014). Mentoring and organizational resilience: A study of manufacturing companies in Rivers State. IOSR Journal of Business and Management (IOSRJBM), 16(10), 1-9.

James, C. R. (2003). Designing learning organizations. Organizational Dynamics, 32(1), 4661. 
Kästle, J. L., Anvari, B., Krol, J., \& Wurdemann, H. A. (2021). Correlation between Situational Awareness and EEG signals. Neurocomputing, 432, 70-79.

Kim, Y. (2020). Organizational resilience and employee work-role performance after a crisis situation: exploring the effects of organizational resilience on internal crisis communication. Journal of Public Relations Research, 32(1-2), 47-75.

Kim, Y. (2021). Building organizational resilience through strategic internal communication and organization-employee relationships. Journal of Applied Communication Research, 1-20.

Kothari, C. R., \& Garg, G. (2014). Reasrch Methodology Methods and Techniques (Third ed.). New Delhi: New Age International (P) Limited

Lengnick-Hall, C. A., Beck, T. E., \& Lengnick-Hall, M. L. (2011). Developing a capacity for organizational resilience through strategic human resource management. Human Resource Management Review, 21(3), 243-255.

Lengnick-Hall, C. A; \& Beck, T. E (2003) Beyond bouncing back: The concept of organizational resilience. Paper.

Lim, J. N., Schultmann, F. \& Ofori, G. (2010) Tailoring Competitive Advantage Derived from the Needs of Construction Firms. Journal of Construction Engineering and Management. $568-580$.

Naseer, S., Khawaja, K. F., Qazi, S., Syed, F., \& Shamim, F. (2021). How and when information proactiveness leads to operational firm performance in the banking sector of Pakistan? The roles of open innovation, creative cognitive style, and climate for innovation. International Journal of Information Management, 56, 102260.

McManus, S., Seville, E., Vargo, J., \& Brunsdon, D. (2008). A Facilitated Process for Improving Organizational

Parashar, M., Singh, S.M. (2005) Innovation Capability, IIBM Management Review, 115123.

Pearce, J. A. \& Robinson, R. B. (2009). Formulation, implementation, and control of competitive

Robbins, S.P \& Coulter, M (2006) Management (9th edition) New York, Prentice Hall

Sachenko, L. (2020). Organizational resilience. Cost optimization approaches.

Sutcliffe, K. M. \& Vogus, T. J. (2003), "Organizing for resilience", in Cameron, K.S., Dutton, J. E.

Tang, J., Tang, Z., \& Katz, J. A. (2014). Proactiveness, stakeholder-firm power difference, and product safety and quality of Chinese SMEs. Entrepreneurship Theory and Practice, 38(5), 1129-1157

Teece, D.J (1980) The Diffusion of Administrative Innovation. Management Science. 26(5), $464-470$

Teece, D. J. (2007). Explicating dynamic capabilities: The nature and Micro foundations of sustainable enterprise performance'. Strategic Management Journal, 28, 1319-1350.

Tran, T. (2008). A conceptual model of learning culture and innovation schema. International Business Journal, 18(3), 287-299.

Umoh G. I. (2009). Management Information System: With Practical Cases. Port Harcourt. Blueprint Limited

Umoh, G. I. \& Amah, E. (2013). Knowledge Acquisition and Organizational Resilience in the Nigerian Manufacturing Organizations. Journal of Information and Knowledge Management, 3(9), 56-63

Weick, K. E. (2002). Puzzles in organizational learning: An exercise in disciplined imagination. British Journal of Management, 13(2), 7-15. 
Weick, K. E., \& Sutcliffe, K.M. (2001). Managing the unexpected: Assuring high performance in an age of welfare industries", International Journal of Gender and Entrepreneurship, 7(1), 2-26

\section{Appendix}

Study population and sample distribution

\begin{tabular}{lll}
\hline Firms & Population & Distributed \\
\hline 3nity Foods Nigeria Limited & 85 & 17 \\
Dufil Prima Foods Ltd & 191 & 38 \\
Coca-Cola Nigeria Limited & 523 & 104 \\
Nigeria Breweries Plc & 588 & 117 \\
Cway Food \& Beverages Nigeria Co. Ltd. & 91 & 18 \\
Bua Sugar Refinery Limited & 136 & 27 \\
Total & $\mathbf{1 6 1 4}$ & $\mathbf{3 2 1}$ \\
\hline
\end{tabular}

